\title{
Characterisation and application of a bovine U6 promoter for expression of short hairpin RNAs Luke S Lambeth ${ }^{1,2}$, Robert J Moore ${ }^{1}$, Morley Muralitharan², Brian P Dalrymple ${ }^{3}$, Sean McWilliam ${ }^{3}$ and Timothy J Doran*1
}

Address: ${ }^{1}$ CSIRO Livestock Industries, Australian Animal Health Laboratory, Geelong, VIC 3220, Australia, ${ }^{2}$ School of Biological and Chemical Sciences, Deakin University, Geelong, VIC 3217, Australia and ${ }^{3}$ CSIRO Livestock Industries, Queensland Bioscience Precinct, St Lucia, QLD 4067, Australia

Email: Luke S Lambeth - Luke.Lambeth@csiro.au; Robert J Moore - Rob.Moore@csiro.au; Morley Muralitharan - morleym@deakin.edu.au; Brian P Dalrymple - Brian.Dalrymple@csiro.au; Sean McWilliam - Sean.McWilliam@csiro.au; Timothy J Doran* - Timothy.Doran@csiro.au

* Corresponding author

Published: II May 2005

BMC Biotechnology 2005, 5:13 doi:10.1186/1472-6750-5-13
Received: 07 February 2005

Accepted: II May 2005

This article is available from: http://www.biomedcentral.com/I472-6750/5/13

(C) 2005 Lambeth et al; licensee BioMed Central Ltd.

This is an Open Access article distributed under the terms of the Creative Commons Attribution License (http://creativecommons.org/licenses/by/2.0), which permits unrestricted use, distribution, and reproduction in any medium, provided the original work is properly cited.

\begin{abstract}
Background: The use of small interfering RNA (siRNA) molecules in animals to achieve doublestranded RNA-mediated interference (RNAi) has recently emerged as a powerful method of sequence-specific gene knockdown. As DNA-based expression of short hairpin RNA (shRNA) for RNAi may offer some advantages over chemical and in vitro synthesised siRNA, a number of vectors for expression of shRNA have been developed. These often feature polymerase III (pol. III) promoters of either mouse or human origin.

Results: To develop a shRNA expression vector specifically for bovine RNAi applications, we identified and characterised a novel bovine U6 small nuclear RNA (snRNA) promoter from bovine sequence data. This promoter is the putative bovine homologue of the human U6-8 snRNA promoter, and features a number of functional sequence elements that are characteristic of these types of pol. III promoters. A PCR based cloning strategy was used to incorporate this promoter sequence into plasmid vectors along with shRNA sequences for RNAi. The promoter was then used to express shRNAs, which resulted in the efficient knockdown of an exogenous reporter gene and an endogenous bovine gene.

Conclusion: We have mined data from the bovine genome sequencing project to identify a functional bovine U6 promoter and used the promoter sequence to construct a shRNA expression vector. The use of this native bovine promoter in shRNA expression is an important component of our future development of RNAi therapeutic and transgenic applications in bovine species.
\end{abstract}

\section{Background}

RNA interference (RNAi), a method of sequence specific gene knockdown, has been used to analyse gene function in plants, invertebrates, and more recently mammalian cells [1-3]. The conserved RNAi pathway involves the processing of double stranded RNA (dsRNA) duplexes into 21-23 nucleotide (nt) molecules known as small interfering RNAs (siRNA) to initiate gene knockdown [46]. Since the discovery of RNAi in animals [7] the use of long dsRNA in lower eukaryotes, especially in the model organism Caenorhabditis elegans, has been used to determine gene function $[8,9]$. However, in mammalian 
systems the cellular uptake of long dsRNA induces an antiviral defence mechanism initiated by interferon (IFN), leading to non-specific translational shutdown and apoptosis [10-12].

This non-specific cellular activity can be circumvented by the direct transfection of either chemically synthesised or in vitro transcribed siRNAs of approximately $21 \mathrm{nt}$ in length into mammalian cells $[1,13]$. These short molecules do not activate the IFN response, but can induce reliable and efficient transient knockdown of target genes $[14,15]$. As a consequence, the development of DNAbased vectors for expression of short hairpin RNA (shRNA) molecules that are processed within the cell to produce active siRNA molecules has progressed rapidly [16-18]. Such DNA expression constructs have achieved highly efficient gene knockdown without induction of the IFN response.

DNA-based vectors offer some additional advantages over chemical and in vitro synthesised siRNA. Vector construction is much less expensive compared to the chemical synthesis of siRNA, selection of transfected cells is possible via antibiotic selection and the option of inducible shRNA transcription is also available. shRNA expression vectors have been engineered using both viral (including retroviral [19], adenoviral [20] and lentiviral [21] vectors), and plasmid systems [16-18]. These vectors often utilize promoters from a small class of pol. III promoters $[22,23]$ to drive the expression of shRNA. Promoters of this type are preferred because they naturally direct the synthesis of small, highly abundant non-coding RNA transcripts, with defined termination sequences consisting of 4-5 thymidines (Ts) and have no requirement for downstream promoter elements [22-24].

The human U6 snRNA promoter is the best studied type III pol. III promoter. It has characteristic promoter elements known as the enhancer and core regions $[25,26]$, and is frequently used in RNAi expression vectors. A total of nine full-length U6 loci have been identified from the human genome [27]. These genes are dispersed throughout the genome and five of these are potentially active, including the previously described human U6 promoter, now denoted U6-1. In the current study we describe the characterisation of the bovine U6 snRNA promoter and its expression of shRNA molecules in bovine cells. We used a PCR based cloning strategy to construct a plasmid vector that features the bovine U6 promoter to drive expression of shRNA molecules directed at the exogenously expressed Enhanced Green Fluorescent Protein (EGFP) and the endogenous bovine gene, glyceraldehyde-3-phosphate dehydrogenase (GAPDH).

\section{Results and discussion}

\section{Characterisation of a bovine U6 promoter}

A bovine BAC clone was identified from GenBank (Accession no. CC528275) that contained a $107 \mathrm{nt}$ region that shared $100 \%$ identity with the human U6 snRNA sequence. A region directly upstream of this sequence also shared significant homology with previously identified human U6 promoter sequences. BLAT analysis revealed that this BAC-clone shared the greatest sequence homology with the human U6-8 promoter located on chromosome 14 [27]. The bovine BAC sequence contained upstream promoter elements consistent with the human U6 promoters and other human pol. III promoters [2730] (Fig. 1). These elements are also present in the mouse U6 promoter used in the pSilencer 1.0-U6 siRNA Expression Vector (Ambion). The location and spacing of these elements is similar for all human U6 promoters and their requirement for pol. III activity is well documented [2830]. The presence of these elements in the bovine BACclone sequence directly upstream of the full-length $\mathrm{U} 6$ snRNA suggested that this region may be an active bovine promoter and could be used effectively to promote shRNA expression.

\section{shRNA expression vector construction}

Using the predicted bovine U6 snRNA promoter sequence as template, PCR based cloning strategies were used to generate shRNA expression vectors targeting EGFP and bovine GAPDH. A two-step PCR reaction was used to produce a vector targeting EGFP (pBovineU6-shEGFP) (Fig. $2 A)$. One-step PCR reactions were used to produce an shRNA expression vector targeting GAPDH (pBovineU6shGapdh), and a non-specific control shRNA (pBovineU6-shScrambled) (Fig. 2B). In addition, using the mouse U6 snRNA promoter sequence from pSilencer1.0 as template in one-step PCR reactions, shRNA expression vectors targeting EGFP (pMouseU6-shEGFP) and bovine GAPDH (pMouseU6-shGapdh) were produced (Fig. 2B).

In all constructs, the first nucleotide of the predicted shRNA was a guanine $(\mathrm{G})$ residue, corresponding to the first nucleotide of the native U6 snRNA. An XbaI restriction enzyme site was engineered downstream of the termination signal to allow screening for full-length shRNA products inserted into pGEM-T Easy (Promega) which lacks an $\mathrm{XbaI}$ site. All final shRNA expression constructs consisted of either the full-length bovine or mouse U6 promoter, a shRNA sense sequence, a loop sequence, a shRNA antisense sequence, a termination sequence and an $\mathrm{XbaI}$ site. 


\section{SPH}

Consensus

Bovine U6

Human U6 - 8

Mouse U6
ATTACCCATAATGCATYGCGG

\author{
-234 CTTACCCAagATCCTACGgGc -214 \\ -247 tTTACCCAgggTGCCCgGgCG -227 \\ -222 ATttCCtAgtAactATaGaGG -202
}

OCT

\author{
ATTTGCAT \\ -209 ATTTGCAT -202 \\ -222 ATTTGCAT -215 \\ -235 ATTTGCAT -228
}

PSE

Consensus

Bovine U6

Human U6 - 8

Mouse U6

\author{
STSACCGTGWST (GT) RAAR $_{(0-3)}$ TG \\ -67 GTCACCaTaACTGTtAAAgAGatG -44 \\ -68 GTCACCGTaAgTagAAtAgGTg $\quad-47$ \\ -73 ctсACCсTаACTGTAaagtAAtTG -50
}

TATA

$\begin{array}{lll}-30 & \text { тттAтAтA } & -23 \\ -31 & \text { ттAтA } & -26 \\ -36 & \text { тАтАAАтAт } & -28\end{array}$

\section{Figure I}

Promoter element sequences of the bovine U6, human U6-8 and mouse U6 promoters. The distal promoter regions containing the SPH and OCT sequences and proximal promoter regions containing the PSE and TATA sequence elements are shown for each promoter. Matches to the consensus sequence delineated at the top of the SPH, OCT and PSE sequences are shown in upper case (SPH consensus is from Schaub et al., 1999 [28], PSE consensus is from Dahlberg et al., 1988 [29] and OCT consensus is from Sturm et al. 1988 [30]). Note that the relative positions of the SPH and OCT elements are switched in the mouse promoter.

\section{Activity of the bovine U6 promoter measured by EGFP knockdown}

To analyse the function of the bovine U6 promoter, the level of EGFP expression in cells cotransfected with pBovineU6-shEGFP and pEGFP-N1 (Clonetech) were directly compared with EGFP expression in cells cotransfected with pBovineU6-shScrambled and pEGFP-N1. An indication of the bovine promoter efficiency was provided by direct comparison to the level of EGFP knockdown by the same shRNA molecule expressed from pMouseU6shEGFP. Prior to validation in bovine cells, both mouse and bovine U6 promoter driven shRNA expression vectors were first validated in Vero cells. As this cell line lacks the interferon $\alpha, \beta$ and $\omega$ genes [31,32], a significant reduction in EGFP expression could be attributed to RNAi and not the result of non-specific inhibition of protein translation characteristic of the IFN response triggered by expressed exogenous dsRNA.

For each transfection condition, knockdown of EGFP in Vero and MDBK cell lines was visualised by fluorescence microscopy (Fig. 3A). Flow cytometry was used to determine the Mean Fluorescence Intensity (MFI) (Fig. 3B). Results in both cell lines showed that cells transfected with either pMouseU6-shEGFP or pBovineU6-shEGFP exhibited large reductions in EGFP expression when compared with cells transfected with pBovineU6-shScrambled.

To ensure that the observed reduction in EGFP expression could be directly attributed to RNAi induced by expressed shRNA, the transcription of these molecules was detected in transfected cells. A radiolabelled RNA probe complementary in sequence to the EGFP shRNA sequence was used in an RNAse protection assay to visualise these molecules. The mouse microRNA (miRNA) miR-16 probe used as a loading control for each condition produced a strong signal at the expected size for all samples (Fig. 3C). The EGFP shRNA was detected only in those samples that were transfected with either of the EGFP shRNA vectors (Fig. 3C). There were no obvious differences in the amount of shRNA produced by either the mouse or bovine $\mathrm{U} 6$ promoters.

\section{Activity of the bovine U6 promoter measured by GAPDH knockdown}

To further validate the function of the bovine U6 promoter for RNAi, shRNA expression vectors targeting the 


\section{(A) Two Step PCR}

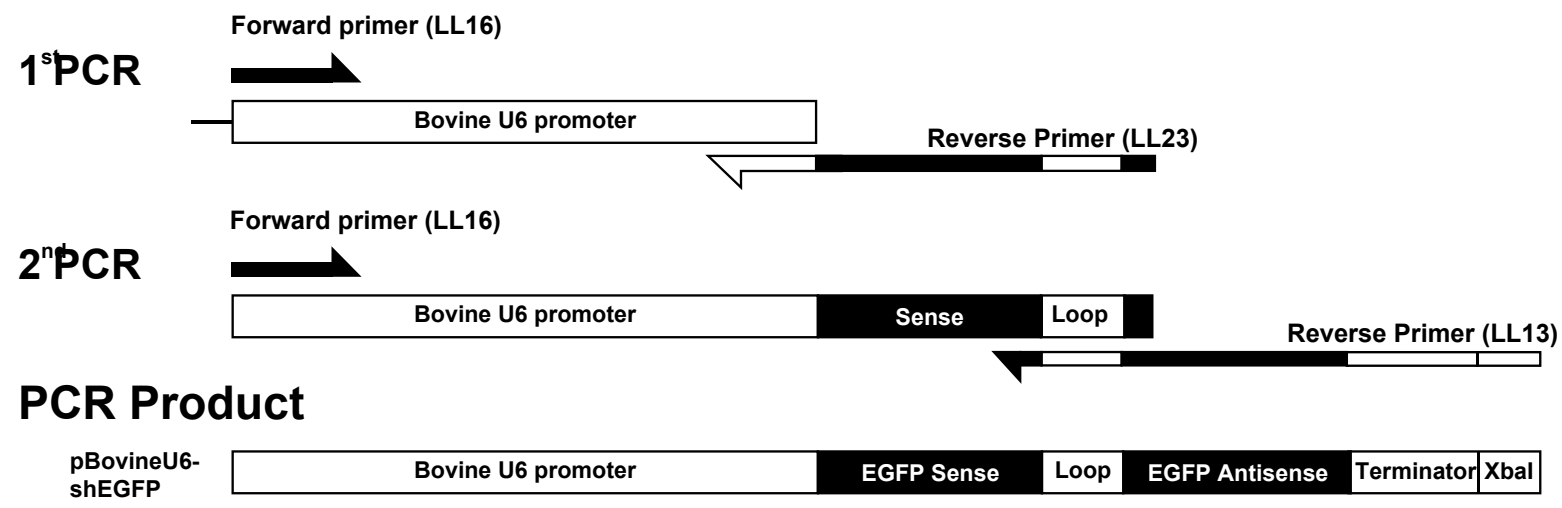

\section{(B) One Step PCR}

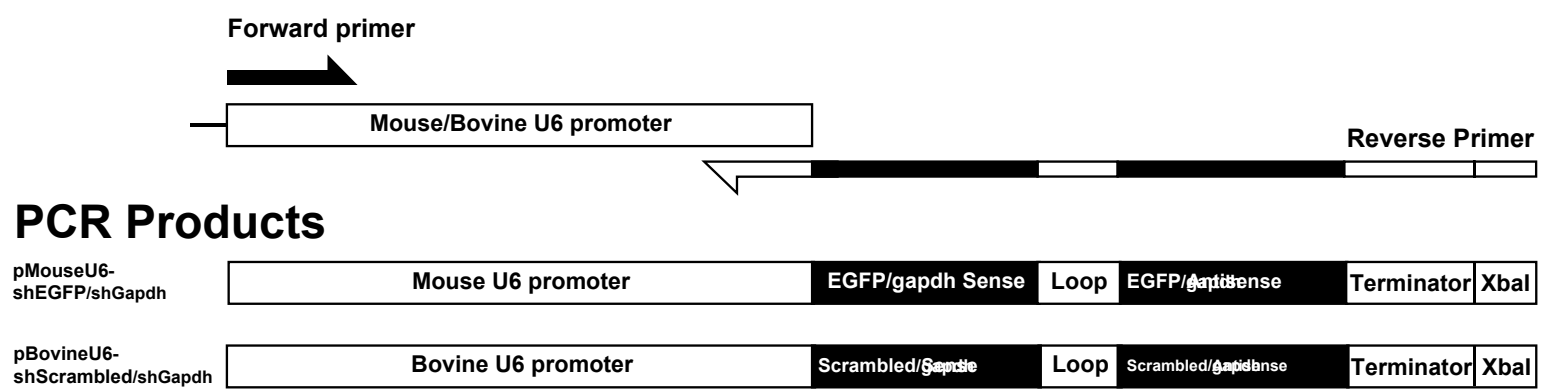

\section{Figure 2}

Schematic representation of the PCR strategies used to produce shRNA expression vectors. (A): The two-step PCR method used to generate PBovineU6-shEGFP. The Ist PCR amplified the bovine U6 promoter, EGFP shRNA sense, loop, and $3 \mathrm{nt}$ of EGFP shRNA antisense using primers LLI6 and LL23. The $2^{\text {nd }}$ PCR amplified the bovine U6 promoter and the remaining EGFP shRNA components including EGFP shRNA antisense, terminator and Xbal using primers LLI6 and LLI3. (B): The one-step PCR method used to generate pMouseU6-shEGFP, pBovineU6-shScrambled, pMouseU6-shGapdh and pBovineU6-shGapdh. PCR reactions used forward primers paired with single reverse primers comprising all shRNA components. All final PCR products consisted of a mouse or bovine U6 promoter, shRNA sense, loop, shRNA antisense, termination sequence and $X$ bal site.

endogenous bovine gene GAPDH were produced. An active shRNA sequence was identified by testing three siRNA sequences directed at this gene. Real-time PCR was used to determine the relative amount of GAPDH in MDBK cells transfected with the three siRNAs compared to cells transfected with the scrambled sequence siRNA control. A similar level of knockdown was achieved for each of the bovine GAPDH siRNAs (Fig. 4A). The most appropriate siRNA sequence, GAPDH \#1, was selected for use in construction of an shRNA vector as this sequence did not contain any runs of T or A residues that may cause premature termination of expressed shRNAs. This sequence was used for both mouse and bovine U6 shRNA vectors (pMouse-shGapdh and pBovine-shGapdh). Using Real-time PCR, the relative amount of GAPDH in MDBK cells transfected with pMouse-shGapdh and pBovineshGapdh was determined by comparison to cells transfected with the irrelevant control plasmid pBovineshScrambled (Fig. 4B). Both vectors produced a very similar level of GAPDH knockdown, although not as effective 
(A)

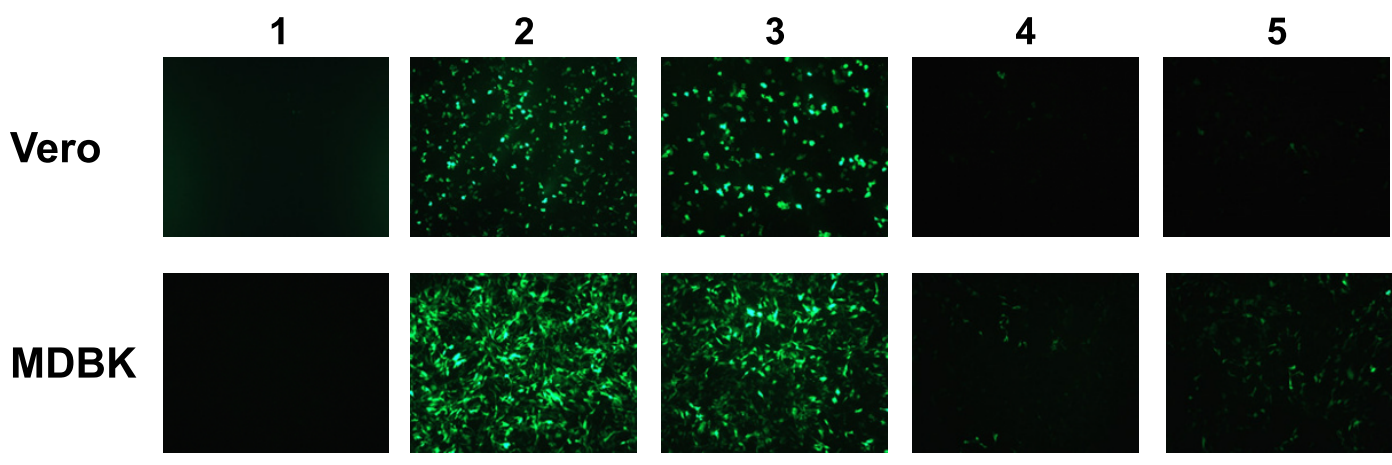

(B)

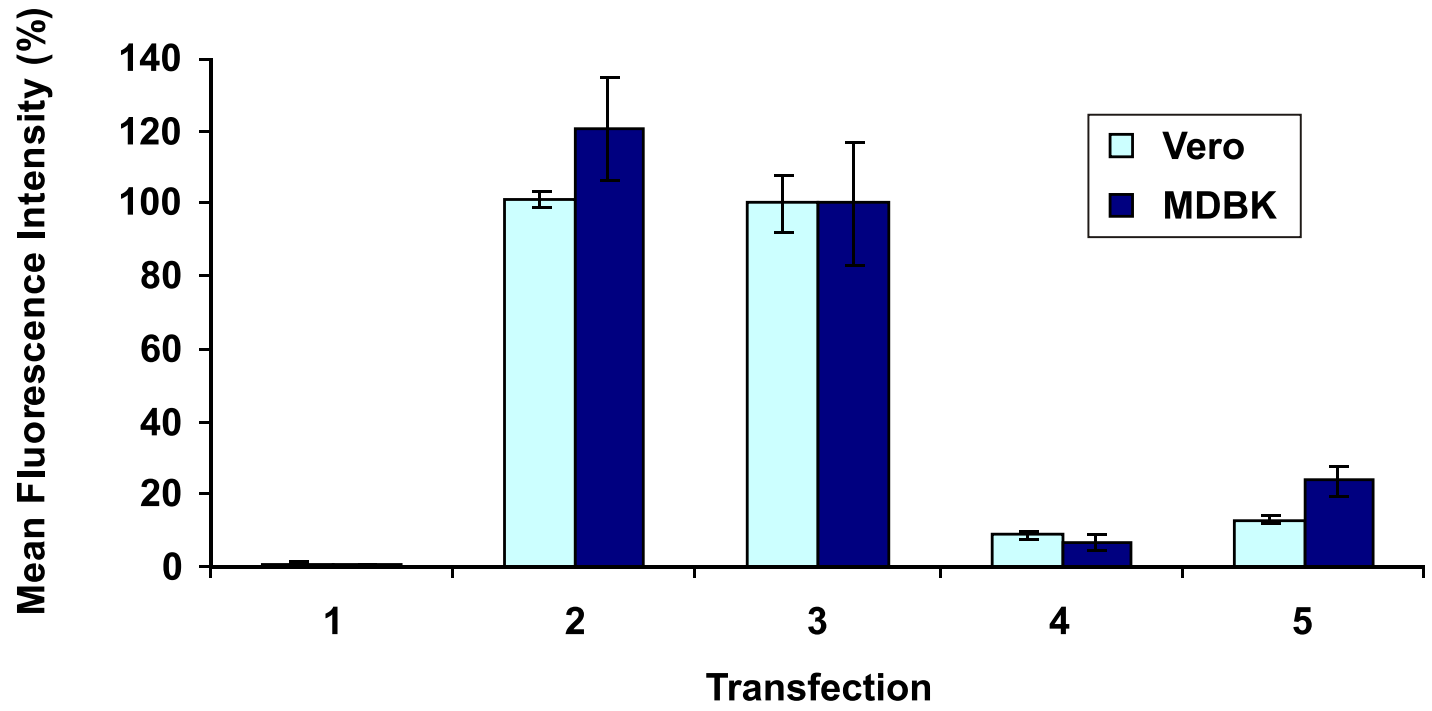

(C) 1 2 3 4 5

miR-16

ShEGFP

\section{Figure 3}

Inhibition of EGFP expression and detection of expressed shRNA from bovine and mouse U6 promoters. (I) transfection free negative control (cells only); (2) transfection of pEGFP-NI; (3) cotransfection of pEGFP-NI and pBovineU6shScrambled; (4) cotransfection of pEGFP-NI and mouseU6-shEGFP; (5) cotransfection of pEGFP-NI and pBovineU6-shEGFP. All transfections were performed in triplicate. (A): Typical fluorescence images of Vero and MDBK cells (Magnifications $\times 100)$. (B): Mean Fluorescence Intensity (MFI) of Vero and MDBK cells 72 hours post-transfection determined by flow cytometry. MFI of EGFP expressed as a percentage of the MFI of pEGFP-NI + pBovineU6-shScrambled. (C): Detection of EGFP shRNAs in Vero cell extracts. Small RNAs were isolated from Vero cells and hybridised to a radiolabelled RNA probe identical in sequence to the EGFP shRNA (shEGFP). shEGFP was detected in lanes 4 and 5 only, and miR-I 6 was used as a loading control. 
(A)

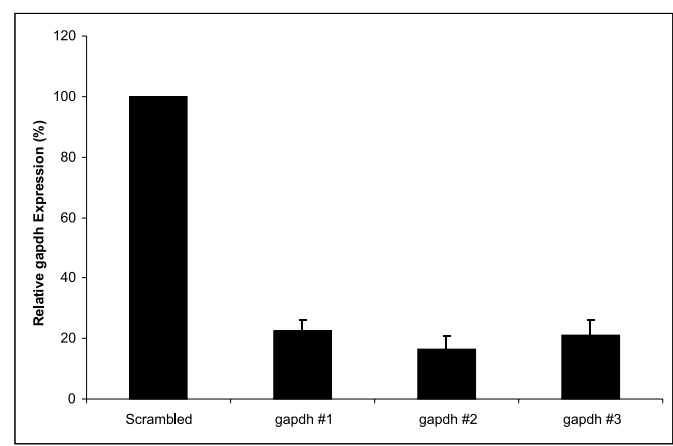

(B)

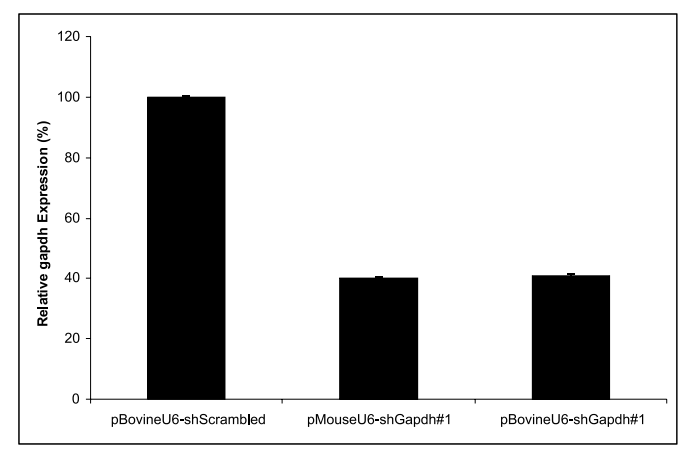

Figure 4

Inhibition of bovine GAPDH expression in MDBK cells. The amount of GAPDH in MDBK cells was determined by Real-time PCR 48 hours post-transfection, expressed as a relative percentage compared to the amount of GAPDH in cells transfected with a scramble sequence siRNA. (A): Cells transfected with either siRNAs directed at bovine GAPDH or a scrambled sequence control siRNA. (B): MDBK cells transfected with pBovine-shScrambled, pMouseshGapdh and pBovine-shGapdh.

as the GAPDH siRNAs. This is probably because the transfection efficiency for siRNAs is generally much greater than that of large plasmid vectors.

\section{Conclusion}

We mined data from the bovine sequencing project and identified a bovine U6 snRNA promoter that is the putative bovine homologue of the human U6-8 snRNA promoter. This pol. III promoter sequence contains a number of functional sequence elements that are characteristic of this type of promoter and are essential for promoter function. The bovine U6 promoter sequence was used in the construction of plasmid based shRNA expression vectors pBovineU6-shEGFP and pBovineU6-shGapdh. These vectors efficiently induced RNAi in MDBK and Vero cells through production of shRNA molecules targeted at the exogenously expressed reporter gene EGFP, and the endogenous bovine gene GAPDH. The use of this promoter sequence and the shRNA vector cloning strategy described here will be advantageous in RNAi functional genomic experiments in bovine cells. The characterisation of this U6 promoter is an important step in the development of novel bovine species specific RNAi based therapeutics. For ethical reasons it is essential to minimise the introduction of non-bovine DNA sequences, consequently this research could be of significance in the transgenic delivery of shRNA molecules in bovine species.

\section{Methods}

\section{Bovine U6 promoter isolation}

Oligonucleotides synthesized in this study are indicated in Table 1. All the oligonucleotides were obtained from GeneWorks Pty Ltd, except for LL91 which was obtained from Proligo, and bovineGpdhPROBE from Applied Biosystems. The bovine BAC-end sequences deposited in the Genome Survey Sequence (GSS) section of GenBank, were compared with the U6 $>95 \%$ identity sequence set for Rfam models RF00026 http://www.sanger.ac.uk/Soft ware/Rfam/index.shtml using BLAST with default parameters and a threshold e-value of 0.01 [33]. All hits detected were scored against the appropriate Rfam covariance model using the cmsearch function of INFERNAL [34]. Flanking repeat elements were identified using Repeatmasker with the minus cow option http://www.repeat masker.org/. Flanking sequences highly conserved between Bos taurus and the human genome sequence were identified using BLAT search (BLAST-like Alignment tool; UC-Santa Cruz genome server [35]) from the UC-Santa Cruz genome bioinformatics site http://genome.ucsc.edu/ cgi-bin/hgBlat.

A region of the bovine genome homologous to a bovine BAC-end sequence (GenBank Accession no. CC528275) predicted to contain a U6 snRNA promoter was amplified from Bos taurus genomic DNA isolated from whole blood using Wizard Genomic DNA Purification kit (Promega). First round PCR amplification used forward primer LL16 with a reverse primer TD 66 designed from the highly conserved human U6 snRNA sequence. This PCR product was then used as template for semi-nested PCR with LL16 and antisense primer TD72 located 11 nt upstream of TD66 in the U6 snRNA sequence. The second round PCR produced a clean band of expected size (507 nt) that was gel purified using QIAquick gel extraction kit (Qiagen), ligated into pGEM-T Easy (Promega) as per the manufacturers instructions and sequenced.

\section{Expression vector construction and shRNA target sites}

A bovine U6 EGFP shRNA construct (pBovineU6-shEGFP) was produced using a two-step PCR approach. The $1^{\text {st }}$ PCR paired LL16 with reverse primer LL23, comprising 
Table I: Synthesized oligonucleotides used in this study

\begin{tabular}{|c|c|}
\hline Name & Sequence \\
\hline LLI6 & 5'-CCAGCAAAGCAACCGATTC-3' \\
\hline TD66 & 5'-GGCCATGCTAATCTTCTCTG-3' \\
\hline TD72 & 5'-TTTTAGTATATGTGCTGCCG-3' \\
\hline LL23 & 5'-ATCTCTCTTGAAGATGAACTTCAGGGTCAGCGGTTTGCCTTTCGTCCACGG-3' \\
\hline LLI3 & 5'-TCTAGATTCCAAAAAAGCTGACCCTGAAGTTCATCTCTCTTGAAGATG-3' \\
\hline TDI34 & $\begin{array}{l}\text { 5'-TCTAGATTCCAAAAAAGCTGACCCTGAAGTTCATCTCTCTTGAAGATGAACTTCAGGG } \\
\text { TCAGCCAAACAAGGCTTTCTCCA-3' }\end{array}$ \\
\hline LL3I & $\begin{array}{l}\text { 5'-TCTAGATTCCAAAAAAAGCGCAGTGTTACTCCACTTCTCTTGAAAGTGGAGTAACACT } \\
\text { GCGCTGGTTTGCCTTTCGTCCACGG-3' }\end{array}$ \\
\hline LBG-as I & 5'-AAGTTCAACGGCACAGTCAAGCCTGTCTC-3' \\
\hline LBG-s2 & 5'-AACTTGACTGTGCCGTTGAACCCTGTCTC-3' \\
\hline LBG-as3 & 5'-AAGGTCATCCATGACCACTTTCCTGTCTC-3' \\
\hline LBG-s4 & 5'-AAAAAGTGGTCATGGATGACCCCTGTCTC-3' \\
\hline LBG-as5 & 5'-AAGCTCATTTCCTGGTACGACCCTGTCTC-3' \\
\hline LBG-s6 & 5'-AAGTCGTACCAGGAAATGAGCCCTGTCTC-3' \\
\hline LL05 & $\begin{array}{l}\text { 5'- TCTAGATTCCAAAAAAGTTCAACGGCACAGTCAAGTCTCTTGAACTTGACTGTGCCGT } \\
\text { TGAACGGTTTGCCTTTCGTCCACGG-3' }\end{array}$ \\
\hline LL06 & $\begin{array}{l}\text { 5'-TCTAGATTCCAAAAAAGTTCAACGGCACAGTCAAGTCTCTTGAACTTGACTGTGCCGTT } \\
\text { GAACCAAACAAGGCTTTCTCCA-3' }\end{array}$ \\
\hline BovineGpdhF & 5'-AACGACCACTTTGTCAAGCTCAT-3' \\
\hline BovineGpdhR & 5'-TCCACCACCCTGTTGCTGTA-3' \\
\hline BovineGpdhPROBE & 5'-TCCTGGTACGACAATGA-3' \\
\hline LL9I & 5'-RGRAURGRARARCUURCRARGRGRGURCRARGRC-3' \\
\hline
\end{tabular}

' $r$ ' prefix to $G, A$ and $C$ represents ribonucleotide, and $U$ indicates ribo-uridine.

the last $20 \mathrm{nt}$ of the promoter sequence, EGFP shRNA sense, loop, and 3 nt EGFP shRNA antisense sequence. This PCR product was used as template for semi-nested PCR to produce the full-length shRNA template, using LL16 and reverse primer LL13 with a short overlapping region, comprising the 4nt EGFP shRNA sense, loop, EGFP shRNA antisense, termination and XbaI.

A mouse U6 EGFP shRNA construct (pMouseU6-shEGFP) was produced using one-step PCR with pSilencer 1.0-U6 siRNA Expression Vector (Ambion) as template. Universal primer M13 Forward was paired with reverse primer TD134, comprising the last $20 \mathrm{nt}$ of the mouse promoter, and all other EGFP shRNA components.

The EGFP shRNA sequence used for both bovine and mouse vectors, had been shown previously to be effective in silencing gene expression [36]. A bovine U6 EGFP scrambled shRNA sequence (pBovineU6-shScrambled) was produced using a sequence that showed no significant homology to available monkey or bovine sequence data. Forward primer LL1 6 was paired with reverse primer LL31 comprising the last $20 \mathrm{nt}$ of the bovine $\mathrm{U} 6$ promoter, and all other EGFP scrambled shRNA components.

Three siRNAs were designed based on the bovine GAPDH sequence obtained from GeneBank (Accession no. U85042) using the criteria described by Elbashir et al.,
2002 (37). Target sites for bovine GAPDH were; GAPDH \#1 (5'-AAGTTCAACGGCACAGTCAAG-3'); GAPDH \#2 (5'-AACTTGACTGTGCCGTTGAAC-3'); GAPDH \#3 (5'AAGGTCATCCATGACCACTTT-3'). To generate siRNAs, oligonucleotides for sense and antisense-strands of each siRNA together with T7 promoter sites were synthesized and siRNAs were produced using the Ambion Silencer siRNA construction kit (Ambion). Oligonucleotides used for each were; GAPDH \# 1: LBG-as1 and LBG-as2; GAPDH \#2: LBG-as3 and LBG-s4; GAPDH \#3: LBG-as5 and LBGs6 (Table 1).

A bovine U6 GAPDH shRNA expression construct (pBovineU6-shGapdh) was generated using a one-step PCR approach. LL16 was paired with LL05 which comprised the last $20 \mathrm{nt}$ of the bovine $\mathrm{U} 6$ promoter and all other GAPDH shRNA sequence components including the GAPDH \#1 siRNA sequence. Similarly, a mouse U6 GAPDH shRNA expression construct (pMouseU6shGapdh) was also generated. M13 universal primer was paired with LL06, which also comprised the last $20 \mathrm{nt}$ of the mouse U6 promoter and all other GAPDH shRNA components. All PCR products for shRNA expression constructs were ligated into pGEM-T Easy (Promega) and sequenced. 


\section{Cell culture and transfection}

MDBK (Madin Darby Bovine Kidney) and Vero (African Green monkey kidney) cell lines were cultured in Eagle's minimal essential medium (EMEM) medium containing $10 \%$ fetal calf serum (FCS), $2 \mathrm{mM}$ glutamine, $10 \mathrm{mM}$ HEPES, supplemented with penicillin $(100 \mathrm{U} / \mathrm{ml})$ and streptomycin $(100 \mu \mathrm{g} / \mathrm{ml})$. All cells were cultured in humidified atmosphere containing $5 \% \mathrm{CO}_{2}$ at $37^{\circ} \mathrm{C}$. Vero cells were grown to approximately $80 \%$ confluence on either 24-well plates (Nunc) for Flow Cytometry, on 8well chamber slides (Lab-Tek) for fluorescence microscopy, or 6-well plates for shRNA detection. Cotransfection with $500 \mathrm{ng}$ for 24-well plates and chamber slides, or 2.5 $\mu \mathrm{g}$ for 6-well plates of plasmid DNA (shRNA plasmids and/or pEGFP-N1 (Clonetech)) was carried out using Lipofectamine 2000 (Invitrogen) according to the manufacturer's instructions. MDBK cells were grown to 80-90\% confluence in $75 \mathrm{~cm}^{2}$ flasks (Corning), harvested and divided into aliquots of $1 \times 10^{6}$ cells per transfection. Approximately $2.5 \mu \mathrm{g}$ of each plasmid was transfected per aliquot by electroporation using a Nucleofector (Amaxa) according to the manufacturer's instructions. Electroporated cells were dispensed into 8-well chamber slides for fluorescence microscopy, 6-well plates (Nunc) for flow cytometry or 24-well plates for Real-time PCR. Transfection of GAPDH siRNAs in MDBK cells grown to approximately $80 \%$ confluence on 24-well plates (Nunc) was achieved using Lipofectamine 2000 with approximately $10 \mathrm{nM}$ of each siRNA.

\section{EGFP and GAPDH knockdown assays}

EGFP expression was monitored at 72-hour post-transfection using fluorescence microscopy (Leica DMLB). Vero and MDBK cells cultured in 8-well chamber slides were washed with PBSA and mounting solution was applied (9:1 glycerol: PBSA). Cells to be analysed by flow cytometry were trypsinized and washed in PBSA. Cells were then resuspended in $200 \mu \mathrm{L} 0.01 \%$ sodium azide and $2 \%$ FCS in PBSA and analysed using a FACScalibur (Becton Dickinson) flow cytometer. Data analysis was performed using CELLQuest software (Becton Dickinson).

Real-time RT-PCR reactions were carried out 48-hours post-transfection. MDBK cells transfected with GAPDH siRNAs and GAPDH shRNA vectors were harvest and cDNA was produced using the Cells-to-cDNA II kit (Ambion) using random hexamers. cDNA $(2.5 \mu \mathrm{L})$ was added to a $22.5 \mu \mathrm{L}$ Real-time RT -PCR master mix containing $12.5 \mu \mathrm{L} 2 \mathrm{X}$ TaqMan Universal PCR Master Mix (Applied Biosystems), $2.5 \mu \mathrm{L}(9 \mu \mathrm{M})$ each of sense primer BovineGpdhF and antisense primer bovineGpdhR, $2.5 \mu \mathrm{L}$ $(2.5 \mu \mathrm{M})$ of TaqMan MGB Probe (bovineGpdhPROBE) (Applied Biosystems) and $2.5 \mu \mathrm{L}$ RNase-free water (Table 1 ). For RNA normalization, an 18s rRNA PCR was performed for each cDNA using the same PCR reagents except for the primers and probes which were the Eukaryotic 18srRNA Endogenous Control (Applied Biosystems). Real-time PCR was carried out in a 7700 Sequence Detection Instrument (Applied Biosystems) using the following thermal cycling profile: $95^{\circ} \mathrm{C} 1 \mathrm{~min}$, followed by 35 cycles of amplification $\left(95^{\circ} \mathrm{C} 15 \mathrm{~s}, 61^{\circ} \mathrm{C} 30 \mathrm{~s}, 68^{\circ} \mathrm{C} 30 \mathrm{~s}\right)$.

\section{shRNA detection}

Detection of EGFP shRNAs was carried by out using an RNAse protection assay on extracts enriched for small RNAs isolated from transfected Vero cells using a mirVana miRNA Isolation Kit (Ambion). The RNA oligonucleotide LL91 was end labelled with [gamma- ${ }^{32} \mathrm{P}$ ] ATP using a mirVana Probe \& Marker Kit (Ambion) and hybridised to the enriched RNAs using the mirVana miRNA Detection Kit (Ambion). The RNA fragments were then separated by electrophoresis on a 15\% denaturing polyacrylamide/ $8 \mathrm{M}$ Urea gel and detected by autoradiography.

\section{Authors' contributions}

LSL carried out all experiments and drafted the manuscript. TJD, RJM and MM participated in design and coordination of the research and revision of the manuscript. BPD and SM helped with bioinformatics and revision of the manuscript. All authors read and approved the final manuscript.

\section{Acknowledgements}

We thank Dr. Jef Hammond and Dr. Sandra Sapats for critically reading the manuscript. The technical assistance provided by Scott Tyack, Terry Wise, Matthew Bruce, Daniel Layton and Tony Pye was also greatly appreciated.

\section{References}

I. Napoli C, Lemieux C, Jorgensen R: Introduction of a Chimeric Chalcone Synthase Gene into Petunia Results in Reversible Co-Suppression of Homologous Genes in trans. Plant Cell I990, 2:279-289.

2. Sharp PA: RNAi and double-stranded RNA. Genes Dev 1999 , I3:|39-|4|.

3. Elbashir SM, Harborth J, Lendeckel W, Yalcin A, Weber K, Tuschl T: Duplexes of 2 I-nucleotide RNAs mediate RNA interference in cultured mammalian cells. Nature 200 I, 4 I I :494-498.

4. Fire A: RNA-triggered gene silencing. Trends Genet 1999, I 5:358-363.

5. Bosher JM, Labouesse M: RNA interference: genetic wand and genetic watchdog. Nat Cell Biol 2000, 2:E3I-E36.

6. Hannon G]: RNA interference. Nature 2002, 4 I 8:244-25I

7. Fire A, Xu S, Montgomery MK, Kostas SA, Driver SE, Mello CC: Potent and specific genetic interference by double-stranded RNA in Caenorhabditis elegans. Nature 1998, 391 :806-8I I.

8. Barstead R: Genome-wide RNAi. Curr Opin Chem Biol 200I, 5:63-66.

9. Ashrafi K, Chang FY, Watts JL, Fraser AG, Kamath RS, Ahringer J, Ruvkun G: Genome-wide RNAi analysis of Caenorhabditis elegans fat regulatory genes. Nature 2003, 42 I:268-272.

10. Williams BR: Role of the double-stranded RNA-activated protein kinase (PKR) in cell regulation. Biochem Soc Trans 1997, 25:509-I3.

II. Stark GR, Kerr IM, Williams BR, Silverman RH, Schreiber RD: How cells respond to interferons. Annu Rev Biochem 1998, 67:227-264.

12. Gil J, Esteban M: Induction of apoptosis by the dsRNA-dependent protein kinase (PKR): mechanism of action. Apoptosis 2000, 5:107-1 |4. 
13. Tuschl T: Expanding small RNA interference. Nat Biotechnol 2002, 20:446-448.

14. Dykxhoorn DM, Novina CD, Sharp PA: Killing the messenger: short RNAs that silence gene expression. Nat Rev Mol Cell Biol 2003, 4:457-467.

15. Duxbury MS, Whang EE: RNA interference: a practical approach. J Surg Res 2004, I I 7:339-344.

16. Brummelkamp TR, Bernards R, Agami R: A system for stable expression of short interfering RNAs in mammalian cells:. Science 2002, 296:550-553.

17. Yu JY, DeRuiter SL, Turner DL: RNA interference by expression of short-interfering RNAs and hairpin RNAs in mammalian cells. Proc Natl Acad Sci U S A 2002, 99:6047-6052.

18. Paddison PJ, Caudy AA, Bernstein E, Hannon GJ, Conklin DS: Short hairpin RNAs (shRNAs) induce sequence-specific silencing in mammalian cells. Genes Dev 2002, I 6:948-958.

19. Devroe E, Silver PA: Retrovirus-delivered siRNA. BMC Biotechnol 2002, 2:15.

20. Huang A, Chen Y, Wang X, Zhao S, Su N, White DW: Functional silencing of hepatic microsomal glucose-6-phosphatase gene expression in vivo by adenovirus-mediated delivery of short hairpin RNA. FEBS Lett 2004, 558:69-73.

21. Abbas-Terki T, Blanco-Bose W, Deglon N, Pralong W, Aebischer P. Lentiviral-mediated RNA interference. Hum Gene Ther 2002, | 3:2 |97-220|

22. Paule MR, White RJ: Transcription by RNA polymerase I and III. Nucleic Acids Res 2000, 28: I 283-1298.

23. Schramm L, Hernandez N: Recruitment of RNA polymerase III to its target promoters. Genes Dev 2002, I 6:2593-2620.

24. Geiduschek EP, Kassavetis GA: The RNA polymerase III Transcription Apparatus. I Mol Biol 200 I, 3 10:1-26.

25. Kunkel GR, Pederson T: Upstream elements required for efficient transcription of a human U6 RNA gene resemble those of $U 1$ and $U 2$ genes even though a different polymerase is used. Genes Dev 1988, 2:196-204.

26. Ma B, Hernandez N: Redundant cooperative interactions for assembly of a human U6 transcription initiation complex. Mol Cell Biol 2002, 22:8067-8078.

27. Domitrovich AM, Kunkel GR: Multiple, dispersed human U6 small nuclear RNA genes with varied transcriptional efficiencies. Nucleic Acids Res 2003, 3 I:2344-2352.

28. Schaub M, Krol A, Carbon P: Flexible Zinc Finger Requirement for Binding of the Transcriptional Activator Staf to U6 Small Nuclear RNA and tRNA(Sec) Promoters. J Biol Chem 1999, 274:2424I-24249.

29. Dahlberg JE, Lund E: The genes and transcription of the major small nuclear RNAs. In Structure and Function of Major and Minor Small Nuclear Ribonucleoprotein Particles Edited by: Birnstiel ML. Berlin Germany: Springer-Verlag; 1988:38-70.

30. Sturm RA, Herr W: The ubiquitous octamer-binding protein Oct-I contains a POU domain with a homeo box subdomain. Genes Dev 1988, 2(I 2A): I582-I599.

31. Diaz MO, Ziemin S, Le Beau MM, Pitha P, Smith SD, Chilcote RR, Rowley JD: Homozygous deletion of the alpha- and beta Iinterferon genes in human leukemia and derived cell lines. Proc Natl Acad Sci U S A 1988, 85:5259-5263.

32. Diaz MO, Pomykala HM, Bohlander SK, Maltepe E, Malik K, Brownstein B, Olopade OI: Structure of the human type-I interferon gene cluster determined from a YAC clone contig. Genomics 1994, 22:540-552.

33. Altschul SF, Madden TL, Schaffer AA, Zhang J, Zhang Z, Miller W, Lipman DJ: Gapped BLAST and PSI-BLAST: a new generation of protein database search programs. Nucleic Acids Res 1997, 25:3389-3402

34. Eddy SR: A memory-efficient dynamic programming algorithm for optimal alignment of a sequence to an RNA secondary structure. BMC Bioinformatics 2002, 3:18.

35. Kent WJ: BLAT-the BLAST-like alignment tool. Genome Res 2002, I 2:656-664.

36. Kim DH, Rossi J]: Coupling RNAi-mediated target downregulation with gene replacement. Antisense Nucleic Acid Drug Dev 2003, I 3:| $5|-| 55$

37. Elbashir SM, Harborth J, Weber K, Tuschl T: Analysis of gene function in somatic mammalian cells using small interfering RNAs. Methods 2002, 26:199-213.
Publish with Biomed Central and every scientist can read your work free of charge

"BioMed Central will be the most significant development for disseminating the results of biomedical research in our lifetime. "

Sir Paul Nurse, Cancer Research UK

Your research papers will be:

- available free of charge to the entire biomedical community

- peer reviewed and published immediately upon acceptance

- cited in PubMed and archived on PubMed Central

- yours - you keep the copyright 